\title{
Improvement of prolificacy in sows by ereation of a " hyperprolific " line and use of artificial insemination : principle and preliminary experimental results
}

\author{
C. LEGAULT, J. GRUAND
}

Station de Génétique quantitative et appliquée, I. N.R. A., C. N. R. Z., 78350 Jouy en Josas

Station expérimentale de Sélection Porcine, 86480 Rouille

The possibilities of genetic improvement of prolificacy in a pig population by creation of a line open to exceptionally prolific Large White and Landrace sows were investigated. Application of the method requires utilization of the boars of the "hyperprolific", line also selected on fattening and carcass traits, in artificial insemination.

The expected theoretical progress was not linear and tended asymptotically towards a maximum, ranging between 5 to $6 \mathrm{p}$. I 100 in purebreeding and $\mathrm{I} 2$ to $\mathrm{I} 4 \mathrm{p}$. IOO in crossbreeding.

The experimental verification of this theory was made by comparing the reproductive ability of the female progeny of ${ }_{4}$ Large White boars, sons of hyperprolific dams and that of Io control boars of the same breed. The young females of the experimental line exhibited a significantly higher ovulation rate $(\mathbf{P}<0.01)$ than the control line (I6.53 vs I 3.96 corporea lutea). The mortality of embryos was significantly higher in the hyperprolific line and therefore the number of embryos or piglets alive per litter did not significantly differ between the groups.

Although the hypothesis of a superposing of additive effects (selection) and non additive effects (heterosis) of the genes on prolificacy has not yet been examined experimentally in the pig, the method suggested seems to be better adapted to production of crossbred females than to improvement of purebred females.

\section{Accuracy of « on farm » testing of young gilts}

M. hamelin, H. PELlois, J.-Y. Fleho, G. GODET

Institut Technique du Porc, Scrvice Sélection, La Motte au Vicomte, R.P. 3, 35650 Le Rheu

Heritabilities of performances measured for on-farm testing of young gilts were estimated. This " on farm " test was done when animals from the same test group averaged $85 \mathrm{~kg}$ of live weight. Each animal was weighed and probed for backfat thickness in six locations with ultrasonics. Then three criteria calculated : 